\title{
A longitudinal study of the job perception-job satisfaction relationship: A test of the three alternative specifications
}

\author{
Chi-Sum Wong* \\ The Chinese University of Hong Kong, Providence University \\ and \\ National Sun Yat-Sen University \\ Chun Hui and Kenneth S. Law \\ Department of Managenent of Organizations, The Hong Kong University of Scienie and Technolagy, \\ Clear Water Bay, Kowlom, Hong Kong
}

\begin{abstract}
Although past job design research bas demonstrated that job perception and job satisfaction are related, there is considerable debate on the causal direction of this relationship. Three alternative specifications of the causal direction can be deduced from three different theories: (1) job perception is the cause (deduced from the job characteristics model); (2) job satisfaction is the cause (deduced from social information-processing theory); and (3) the two constructs are reciprocally related (deduced from cognitive social learning theory). Past studies have not provided a comparative test of these three alternative specifications. Thus, the causal relationship between these two constructs remains nebulous. $A$ longitudinal design was employed to examine the relationship between job perception and the different components of job satisfaction (i.e. overall, intrinsic and extrinsic) with data collected over a two-year time span. Structural equation modelling was conducted to investigate the cross-lagged relationships between job perception and job satisfaction. Results indicated that job perception was reciprocally related to overall and intrinsic job satisfaction. Implications for job design research and practices are discussed.
\end{abstract}

Job design research in the past three decades has generated many insights into the relationship between job characteristics and job satisfaction. For example, the well-known and widely researched job characteristics model (Hackman \& Oldham, 1976, 1980) proposes five core motivational job characteristics: skill variety, task significance, task identity, feedback and autonomy. Past research has demonstrated that these motivational job characteristics are related to job satisfaction (for meta-analyses, see Fried, 1991; Fried \& Ferris, 1987; Loher, Noe, Moeller \& Fitzgerald, 1985; Stone, 1986). What is less clear, however, is the direction of * Requests for reprints should be addressed to Chi-Sum Wong, Department of Management, The Chineso University of Hong Kong, Shatin, N.T., Hong Kong. 
causality between the perception of these motivational characteristics (job petception) and job satisfaction. Indeed, there has been considerable debate over the causal relationship between job perception and job satisfaction among various theories. Three alternative specifications can be deduced from three different theories: the job characteristics model, social information-processing theory and cognitive social learning theory. Unfortunately, past job design studies failed to provide definitive comparative tests of these three specifications, leaving the causal relationship between job perception and job satisfaction nebulous. The present study is an attempt to compare the three in a longitudinal framework. It should be noted that the scope of job design theories is much larger than the job perception-job satisfaction relationship. However, longitudinal field experiments in job design have shown that job redesign may have specific rather than wide-ranging effects on employee attitudes and behaviour (e.g. Cordery, Mueller \& Smith, 1991; Schaubroeck, Ganster, Sime \& Ditman, 1993; Wall, Kemp, Jackson \& Clegg, 1986). Therefore, the present study will focus on the job perception-job satisfaction relationship, which has received most of the research attention in the job design literature.

\section{Causal direction between job perception and job satisfaction}

The first alternative specification is based on the job characteristics model (JCM), which emphasizes the effects of objective motivational job characteristics on employee affective outcomes such as job satisfaction. Since the JCM suggests a strong correspondence between objective job characteristics and subjective job perception (cf. Stone, 1992), one may argue that objective job characteristics will affect job perception, which, in turn, leads to intrinsic job satisfaction (cf. Hulin \& Blood, 1968; Stone, 1976). The model does not hypothesize a direct relationship between objective job characteristics and extrinsic job satisfaction (i.c. satisfaction with facets other than the job itself, such as pay and promotion opportunities), nor between objective job characteristics and overall job satisfaction.

The other two alternative specifications are based on theories that emphasize the processes through which job perception and attitudes (e.g. job satisfaction) are formed, and the effects of social information on these processes. Social information-processing theory (SIP) argues that overall job attitudes, of which job satisfaction is one, will initiate a rationalizing process through which individuals will 'make sense' of their situation by cognitively constructing characteristics of their job that are consistent with the social context (Salancik \& Pfeffer, 1978; Thomas \& Griffin, 1983). In other words, this theory suggests that employees develop a generalized reaction to the work environment (i.e. attitudes) based on information gained from their social contexts. This global impression about the social contexts will then affect the perception of their jobs. In this case, job perception is the effect of job satisfaction rather than the cause. SIP theory does not distinguish overall job satisfaction from its components. Thus, based on SIP theory, one may argue that overall job satisfaction (including both intrinsic and extrinsic aspects) should have causal effects on job perception. 
The final alternative specification is based on the cognitive social learning theory (CSL) introduced by James and his colleagues (e.g. James, Hater, Gent \& Bruni, 1978; James \& Jones, 1980; James \& Tetrick, 1986). According to this theory, employees will form their job perception by assigning unique meanings to their work situations based on their jobs and other relevant situational attributes. They will then formulate attitudes based on these perceptions and adjust their assignment of meanings if inconsistencies exist betwcen their perception and attitudes. This interactive adjustment is a social learning process for employees to maintain consistencies between perception and attitudes. Thus, based on this theory, one may argue that job perception and job satisfaction are teciprocally related. Similar to the JCM, CSL theory also deals explicitly with the relationship between job perception and intrinsic job satisfaction. In measuring job satisfaction, for example, only 'items associated directly with job and task events' were used by James \& Jones (1980, p. 110). Thus, according to this theory, only the reciprocal relationship between job perception and intrinsic job satisfaction is relevant.

There are important theoretical and practical implications for understanding the correct causal direction between job perception and job satisfaction. Theoretically, it is important to distinguish the differences among the theories behind the three alternative specifications. If they are competing and mutually exclusive theories, we may reject two of these theories and conclude that one theory is the correct description of the reality. However, the three theories do not appear to be mutually exclusive in their specifications of the job perception-job satisfaction telationship. For example, as pointed out above, the JCM and CSI theories discuss intrinsic job satisfaction, while SIP theory concerns overall job satisfaction. It is possible that job perception affects intrinsic job satisfaction while extrinsic job satisfaction affects job perception. If this is the reality, then both the JCM and SIP theories are correct and they are not competing with each other. The JCM can be further developed by incorporating the job perception-extrinsic job satisfaction relationship, while SIP theory can incorporate the distinction between intrinsic and extrinsic job satisfaction. Thus, by revealing the correct causal direction between job perception and job satisfaction, it is possible to clarify and integrate these theories so that a better understanding of the whole picture of reality can be achieved.

Larly job design researchers have pointed out the important distinction between intrinsic and extrinsic job satisfaction in the job design area. In clarifying an early job design review by Hulin \& Blood (1968), Stone (1976) stated:

if job enrichment or job enlargement has any impact on job satisfaction, the facet of satisfaction most likely to be influenced by such efforts is satisfaction with the work itself . . It is recognized that job enlargement or enrichment may impact upon other facets of job satisfaction (e.y., satisfaction with pay, promotions, co-workers, supervision, etc.). These other facets of job satisfaction do not, however, appear to be as relcvant to the issuc considered in the Hulin and Blood review as satisfaction with the work itself (p. 148).

In a meta-analysis for both field and laboratory job design studics, Stone (1986) concluded that job perception was more closely related to intrinsic job satisfaction than to overall job satisfaction. Unfortunately, this difference concerning the 
construct of job satisfaction has not been rccognized in more recent job design studies. For example, Mathieu, Hofmann \& Farr (1993), in testing the three theories, measured both the intrinsic and extrinsic facets of job satisfaction and used them as indicators for the construct. However, because this study does not make the distinction between intrinsic and extrinsic job satisfaction, it provides little information for possible development and integration of the three theories in their specifications of the job perception-job satisfaction relationship.

For job design practitioners, the causal direction between job perception and job satisfaction will affect their choice of interventions to enhance desirable outcomes. If job perception is the effect rather than the cause of job satisfaction, job design programmes concentrating only on the manipulation of job characteristics in order to cultivate favourable job attitudes such as job satisfaction may be ineffective. On the other hand, if job perception causes not only intrinsic job satisfaction but also extrinsic job satisfaction, job design programmes may provide an alternative means of influencing extrinsic job satisfaction than the manipulation of extrinsic rewards.

Despite the importance of the direction of the causal relationship between job perception and job satisfaction, previous research on this topic has not provided a clear distinction between intrinsic and extrinsic job satisfaction and thus has failed to provide adequate comparative tests of the three alternative specifications. In the following section, previous research on testing the direction of the causal relationship between job perception and job satisfaction is reviewed.

\section{Past studies}

Two major research designs that have been used in past studies to test the causal relationship between job perception and job satisfaction are experimental studies and cross-sectional, non-recursive structural equation modelling. Lnfortunately, the first type of design cannot test reciprocal relationships or compare the three alternative specifications simultaneously, while the interpretation of results of the second type of design raises serious problems.

The first type of studies has employed experimental designs in which either objective job characteristics (e.g. Farh \& Scott, 1983; Farr, 1976; Griffin, 1983; Kim, 1980; Lawler, Hackman \& Kaufman, 1973; O'Connor, Arnold \& Bhagat, 1981; Orpen, 1979; Terborg \& Davis, 1982; Wall \& Clegg, 1981) or job satisfaction (e.g. Caldwell \& O'Reilly, 1982; Weiss \& Shaw, 1979) are manipulated, and the effects of one construct on the other are examined. Although these experimental studies have provided valuable evidence on the causal linkage between job perception and job satisfaction, they have not provided a comparative test of the three alternative specifications. Rather, these studies typically provide evidence to support one theory only (i.c. either the JCM or SIP theory). Consequently, the potential reciprocal relationship between job perception and job satisfaction suggested by CSL theory has never been tested in these studies.

The second type of study is a more recent innovation and involves the application of either the two-stage least square method or structural equation modelling to draw causal inferences from field studies. These methods are capable of testing reciprocal relationships among constructs (Jöreskog, \& Sörbom, 1989), 
and models with different specifications of the causal relationships among the constructs can be compared statistically (Anderson \& Gerbing, 1988; Bollen, 1989). However, the three previous field studies that have employed the two-stage least squares method or structural equation modelling have used cross-sectional data (James \& Jones, 1980; James \& Tetrick, 1986; Mathieu et al., 1993). The use of cross-sectional data undermines the power of causal inference, particularly that concerning reciprocal causation. The effects identified from cross-sectional data may be inflated due to the methodological artifact of priming or to the consistency effects associated with simultaneous measurement (Meyer, Allen \& Gellatly, 1990). It is also difficult to interpret reciprocal relationships in cross-sectional data. Hunter \& Gerbing (1982) argue that:

If $X$ and $Y$ have an effect on each other, then $X$ has an impact on $Y$; which has an impact on $X$, which has an impact on $Y$. That is, by the traditional recursive system rules, $X$ not only has a direct effect but has an indirect effect (through itself!) on $Y$ as wcll. Furthermore, this cycling can go on as many steps as can be imagined. In reality, there is no such instantaneous cycling process (pp. 288-289).

This viewpoint is, in fact, well addressed by many econometricians (e.g. Levacic, 1976; Persson \& Tabellini, 1990) who used the term 'static analysis' to represent models being tested using cross-sectional data. For example, Levacic (1976) stated that 'Static analyis is timeless ... Static equilibrium does not exist in the real world since the values of parameters are constantly changing and instantaneous adjustment does not occur' (p. 8). To illustrate their argument, let us consider the finding of Mathieu et al. (1993). Their model included the following significant parameters (p. 383):

$$
\text { Job perception }=.595 \times \text { Job satisfaction }+.272 \times \text { Technology }
$$

Job satisfaction $=.600 \times \mathrm{Job}$ perception $+.073 \times \mathrm{Size}+.079 \times$ Education

Let us assume that technology, department size and education level are kept at the constant level of 1 . The problem of a cross-sectional model is that it will not show what job satisfaction should be when job perception is equal to a specific value, say 1 . This is because when job perception is 1 , job satisfaction should be .752 ; but when job satisfaction is .752 , job perception should then be .719 . This cycling process representing the indirect effects of job satisfaction on job perception and vice versa can cycle infinitcly, making it impossible to have a final stabilized value of job satisfaction. Furthermore, the chances for drawing a wrong conclusion from the statistical tests of reciprocal relationships in non-recursive models using cross-sectional data may be well above the alpha level suggested by these tests (Wong \& Law, 1996).

Facing these difficulties, many researchers (e.g. Anderson \& Williams, 1992; Hunter \& Gerbing, 1982; Mathieu, 1991; Williams \& Podsakoff, 1989) recommend the use of longitudinal designs to examine reciprocal causation. This call for longitudinal designs to examine reciprocal relationships in field settings is particularly relevant to the job perception-job satisfaction causal relationship. This is because employees need time to develop their job perception and job attitudes 
(Campion \& McClelland, 1993; Griffin, 1991). Griffin investigated the effects of job redesign on the attitudinal outcomes of clerical workers over time, while Campion \& McClelland studied the same issue and included both clerical workers and managers in their sample. Both studies found that the influence of job redesign on job satisfaction was initially high, but its effect declined over time. Griffin found that the level of job satisfaction after redesign gradually stabilized to the same level as before the redesign. Campion \& McClelland discovered that the level of job satisfaction declined after redesign and remained lower than it had been before the redesign. Campion \& McClelland argued that the initial improvement in job satisfaction may be due to a transient Hawthorne Effect (Mayo, 1933). The actual effect of job redesign may be appreciated only over a period of time as employces develop a more thorough understanding of the changes in job content.

In order to overcome the limitations of both types of study, the three alternative specifications of the job perception-job satisfaction relationship should be compared simultaneously in a single longitudinal investigation. The distinction among intrinsic, extrinsic and overall job satisfaction should also be made clear. $A$ longitudinal design would allow for more confidence in inferring causal relationships. Furthermore, examining the stability of the effects of job perception and job satisfaction over time before drawing conclusions about their causal relationships is also important. Unfortunately, none of the previous job design studies that investigated the causal relationship between job perception and job satisfaction have provided such a test.

\section{The present study}

From the above discussion it is clear that previous studies on the job perceptionjob satisfaction relationship provide only weak, if any, comparative tests of the three alternative specifications. The present study examined these specifications using a longitudinal design. Furthermore, we examined the stability of both job perception and job satisfaction to ensure that the Hawthorne Effect was climinated in our analysis. Longitudinal data over a 24 -month period were collected at one-year intervals. This time frame was chosen based on a recommendation by Campion \& McClelland (1993). Their wotk highlights the deficiencies of past studies with time frames under a year while stressing the importance of studying job design effects over a longer term. Furthermore, we used a job satisfaction measure that tapped intrinsic, extrinsic and ovcrall job satisfaction, in order to test the job perception-job satisfaction relationship deduced from the threc theories.

\section{Method}

\section{Sampling procedures}

The research participants were graduates of a major university in Hong Kong from 1986 to 1990 , who returned three questionnaires in the 24 -month data collection period. In all three questionnaires, the participants were asked not to complete the questionnaire if they did not hold a full-time job. Except for the end of the second and third questionnaires, where the participants were asked to indicate if they had changed jobs since the previous survey, the questionnaires used in all three surveys 
were identical. The first questionnaire, which included reply envelopes, was sent to 4274 research participants in September 1991, and 1687 questionnaires (39.5 per cent) were returned. One year later (September 1992), the same questionnaire was sent to those participants whose responses were obtained in the first survey, and 785 questionnaires ( 46.5 per cent) were returned. In September 1993 , questionnaires were sent to those participants from whom data were obtained in the second survey, and 485 questionnaires (61.8 per cent) were returned. The responsc rate for cach questionnaire compares favourably with response rates for most ficld studies, including longitudinal studics.

Because we were investigating the job perception-job satisfaction relationship over time, only research participants who did not change jobs during the three surveys were included in our analyses. A total of 304 research participants did not change their jobs over the 24 -month period. After listwise deletion for missing values, 196 questionnaires were usable for the purposes of structural equation modelling.

\section{Cross-cultural issues and questionnaire design}

Four versions of the questionnaire were used, each version varying according to the language and the response scale used. First, both Finglish and Chinese versions of the questionnaircs were used. The Chinese version was back-translated into Fnglish (Brislin, 1970), and the two versions were found to be comparable. Second, two sets of response scales were used for each language version: a five-point scale and a four-point scale without the neutral point. There were two reasons for adopting the four versions. First, by comparing the responses of the two language versions, we were able to determine whether research participants wore interpreting the Chinese and English questions in a similar way. Second, we could examine the response bias of the Chinese research participants induced by different scales. Past studies have found that people in Hong Kong are reluctant to make known their opinion on politically sensitive matters (e.g. Hoadley, 1970; Podmore, Chaney \& Golder, 1975) and this lack of extreme response style has also been found in several other Fastern populations (c.g. Chun, Campbell \& Yoo, 1974). Chun et at. (1974) point out that this lack of extreme response style in survey research will lower the true variances and covariances of the underyling constructs. This will lead to misleading results when statistical procedures involving the structures of variances and covariances are employed. It has been argued that in Tawan and Hong Kong the reluctance among Chinese people to express opinions may be reinforced if an odd number responsc scale is used (c.g. Yang, 1982). Thus, it is important to examine whether or not this effect is present.

To examine the language and the response scale effects, we conducted subgroup analyses. (Overall, we found no major differences for the variances (by $F$ tests, $p>.10$ ), correlations among measures (by the testing procedure described by Cohen \& Cohen, 1975, pp. 50-52, p> 10), and factor structure (by confirmatory factor analyses) of the job perception and job satisfaction measures among the four versions of questionnaires, with the exception of one item related to job feedback. It appeared that the English version of this could have been misinterpreted by research participants. 'This item was dropped for subsequent analyses. Thus, we concluded that language and response scale effects were not likely to be operating in our final sample. Subgroup data were then standardized and collapsed to form the sample for the present study. Table 1 reports the means and standard deviations of the variables used in this study for the four-point and five-point subgroups.

\section{Measures}

Job pereption. The Job Diagnostic Survey, measuring the five core motivational job characteristics, was adopted (Hackman \& Oldham, 1975). Specifically, three items for each characteristic were used, with the exception of job feedback because one item had been dropped. Internal consistency reliabilitics of individual job characteristics in the three time waves were: $.68, .68$ and .75 for autonomy; $.76, .77$ and .87 for task identity; $.69, .65$ and .78 for skill variety; $.80, .82$ and .81 for task significance; and .66 , .65 and .72 for feedback. These reliability estimates were similar to those found in past studies (for a summary of reliability estimates, see Cook, Hepworth, Wall \& Warr, 1981).

Job satisfaction. Job satisfaction was measured by the short form of the Minnesota Satisfaction Questionnaire (Weiss, Dawis, England \& Lofquist, 1967). This established scale provided three 
Table 1. Means and standard deviations (in parentheses) of the measures

\begin{tabular}{lcc}
\hline & $\begin{array}{c}\text { Four-point subgroup } \\
(N=92)\end{array}$ & $\begin{array}{c}\text { Five-point subgroup } \\
(N=104)\end{array}$ \\
\hline JPI & $21.81(11.48)$ & $46.28(20.80)$ \\
JP2 & $22.03(9.49)$ & $49.07(21.40)$ \\
JP3 & $26.41(13.42)$ & $48.91(23.06)$ \\
OJS1 & $2.73(0.36)$ & $3.43(0.50)$ \\
OJS2 & $2.65(0.41)$ & $3.50(0.50)$ \\
OJS3 & $2.86(0.37)$ & $3.43(0.56)$ \\
IJS1 & $2.80(0.40)$ & $3.56(0.54)$ \\
IJS2 & $2.78(0.42)$ & $3.65(0.49)$ \\
IJS3 & $3.00(0.40)$ & $3.63(0.60)$ \\
EJS1 & $2.62(0.41)$ & $3.24(0.59)$ \\
EJS2 & $2.46(0.49)$ & $3.27(0.64)$ \\
EJS3 & $2.65(0.42)$ & $3.13(0.64)$ \\
& & \\
\hline Key for all tables. JP=job perception; OJS = overall job satisfaction; IJS $=$ intrinsic job \\
satisfaction; EJS=extrinsic job satisfaction. 1,2 and 3 denote the first, second and third \\
data collection, respectively.
\end{tabular}

indicators of job satisfaction: intrinsic (12 items), cxtrinsic ( 8 items) and overall (all 20 items). Internal consistency reliabilities for these indicators over the threc time waves were: $.87, .87$ and .88 for overall job satisfaction; $83, .83$ and .85 for intrinsic job satisfaction; and $.75, .75$ and .77 for extrinsic job satisfaction. These reliability coefficients are similar to those found in past studies (Cook et al., 1981).

\section{Preliminary analyses}

Although the average response rate for each survey is 49.3 per cent, the final sample size that was used to examine the job perception-job satisfaction relationship was only 196 due to attrition and participant job changes. We therefore conducted three preliminary analyses to check the representativeness of this final sample. First, although the research participants were quite homogeneous in their backgrounds, they may have differed in three aspects: gender, undergraduate major and ycar of graduation. The proportions of respondents in these three aspects for the three surveys are all very similar to the general population. For example, the percentage of males in the population and in the three surveys is $51.0,52.0,49.5$ and 49.9 per cent, respectively. Chi-square test on these three aspects indicate no statistical differences $(p>.10)$ for the three surveys. Second, we compared the level of job perception and job satisfaction in the first and second surveys for those who responded in the next survey with those who did not. No significant differences are observed $(p>10)$. Thus, research participants who responded to all three surveys did not appear to be a biased sample.

Third, concerning the issue of changing jobs, we compared the overall, intrinsic and extrinsic job satisfaction, job perception and pay level for those who had changed jobs in the second and third surveys with other research participants who remained in the same jobs. Results indicate that before changing their jobs, research participants who changed their jobs had a significantly lower level of ovcrall, intrinsic and extrinsic job satisfaction $(p<.05)$. No significant difference is found for job perception $(p>.10)$. After changing their jobs, the two groups did not differ in overall and intrinsic job satisfaction or in job perception. However, extrinsic job satisfaction remained lower for those who had changed their jobs. Consistent with this finding, the pay levels for those who changed jobs are statistically lower both before and after changing their jobs. Although turnover appears to be related 


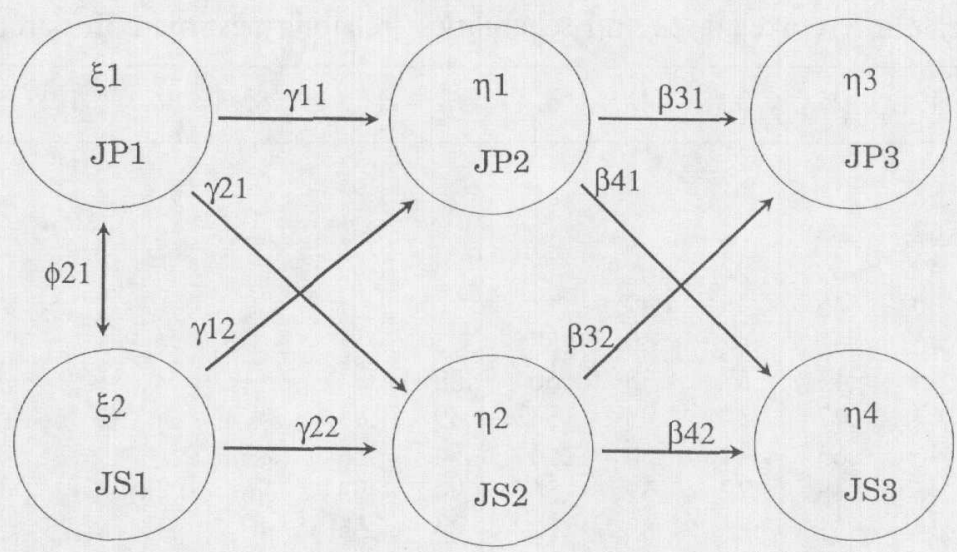

Figure 1. The general cross-lagged structural model depicting relationships between job perception and job satisfaction. Key. JP = job perception; JS = job satisfaction. 1, 2 and 3 denote the first, second and third waves of data collection, respectively.

to job satisfaction, these results show that the job pereeption for those who did not change jobs over the two-year period was similar to that of respondents who did change their jobs.

\section{Model specification}

We employed structural equation modelling using LISRF. . 8.12a to examine the causal models in the present study (Jöreskog \& Sörbom, 1993). Figure 1 shows the baseline structural model adopted in this study. This cross-lagged model is adupted based on the recommendation of Hunter \& Gerbing (1982). The cross-lagged analysis provides the most uncquivocal test of causality.

To compare the three alternative specifications, we conducted three separate sets of analyses based on each of the three components of job satisfaction: overall, intrinsic and extrinsic. Even though none of the three theories directly involves extrinsic job satisfaction, an analysis of how it relates to job perception creates a morc complete picture about the relationship between job perception and job satisfaction. The research participants involved in these three sets of analyses were identical, as were the models, cxcept for what constituted job satisfaction in each casc. Examination of the three models separately for each indicator allows for a comparison of the relationship between job perception and the three components of job satisfaction.

The motivating potential score (MPS), a theory-based operationalization of job perception from individual job characteristics discussed in the job design literature, was used to index job perception. Mathematically, the MPS is the average of task identity, skill varicty and task significance, multiplied by autonomy and feedback. This mathematical calculation of the MPS precluded us from adopting the normal measurement specification for covariance structure models. Instead, we used a covariance structure model with single indicators for each latent variable. This single indicator method was developed by James, Mulaik \& Brett (1982) and Kenny (1979), and has been used in past studies (c.g. Anderson \& Williams, 1992; Williams \& Hazer, 1986). As our primary objective was to examine the structural relationship between latent variables, the choice not to use the full covariance model was considered not to be damaging to our analyses. Because we used cstablished scales with acceptable reliabilities, we assumed that the constructs were well measured. We created a single indicator for job perception for each of the three data collection points, based on the specifications of MPS, and averaged the item scores for overall, intrinsic and extrinsic job satisfaction within each time wave to formulate a single indicator for each of these three components of job satisfaction. Mathematically; the factor loading equals the square root of the reliabilities, whereas the crror variances equal the 
Table 2. Scale intercorrelations and reliabilities (reliability estimate in parentheses)

\begin{tabular}{lcccccccccccc}
\hline & 1. & 2. & 3. & 4. & 5. & 6. & 7. & 8. & 9. & 10. & 11. & 12. \\
\hline 1. JP1 & $.88)$ & & & & & & & & & & \\
2. JP2 & .62 & $(.88)$ & & & & & & & & & & \\
3. JP3 & .49 & .60 & $(.92)$ & & & & & & & & & \\
4. OJS1 & .59 & .45 & .35 & $(.87)$ & & & & & & & & \\
5. OJS2 & .46 & .62 & .42 & .60 & $(.87)$ & & & & & & & \\
6. OJS3 & .43 & .43 & .67 & .53 & .60 & $(.88)$ & & & & & & \\
7. IJS1 & .64 & .47 & .37 & .93 & .54 & .49 & $(.83)$ & & & & & \\
8. IJS2 & .46 & .65 & .44 & .58 & .94 & .54 & .58 & $(.83)$ & & & & \\
9. IJS3 & .45 & .48 & .72 & .51 & .56 & .94 & .53 & .56 & $0.85)$ & & & \\
10. EJS1 & .34 & .31 & .23 & .83 & .52 & .44 & .55 & .40 & .33 & $(.75)$ & & \\
11. EJS2 & .36 & .45 & .30 & .52 & .89 & .56 & .38 & .67 & .45 & .58 & $(.75)$ & \\
12. EJS3 & .28 & .24 & .43 & .42 & .51 & .84 & .29 & .37 & .61 & .49 & .60 & $(.77)$ \\
\hline
\end{tabular}

variance of the measure multiplied by the value (1 - reliability) (Kenny, 1979). Because standardized data were used in this study, the error variances were, in effect, the value of: 1 - reliability.

\section{Analytic strategy}

To test for the stability of job perception and job satisfaction, and that of the causal dircetion between them, we compared a series of the nested models. Models are nested when one can derive a second model by eliminating parameters in the first model and/or by imposing cquality constraints on the parameters in the first model. Nested models can be compared using the chi-square test. If the two nested models arc significantly different from each other, we may then conclude that the relationship omitted in the second model contributes significantly to the first model.

The stability of job perception and job satisfaction over time, and that of their effects on each other, were assessed by imposing the equality constraint on the paths involving the same variables (i.e. for job perception: $\gamma 11=\beta 31$; for job satisfaction: $\gamma 22=\beta 42$; for job perception to job satisfaction: $\gamma 21=\beta 41$; for job satisfaction to job perception: $\gamma 12=\beta 32$ ). A conclusion about the stability of effects may be drawn if the chi-square change of this constraincd model docs not differ significantly from that of the unconstrained model. Causal effects were tested by omitting the paths involving iob perception to job satisfaction (i.e. $\gamma 21$ and $\beta 41$ ) or job satisfaction to job perception (i.c. $\gamma 12$ and $\beta 32$ ) from the models shown in Fig. 1. If the model chi-square change is significant, then the paths should be retained and a conclusion regarding a causal effect can be drawn. We reported the compartive fit index recommended by Gerbing \& Anderson (1993) as the rcference for the overall fit of the models. The model fit for the cross-lagged models, however, was not expected to be good because our data were collected in one-year intervals. The sacrifice in model fit was justified by the objective to examine the effects of the constructs over a longer time period and to identify unequivocal reciprocal causality.

\section{Results}

\section{Stability of effects}

Correlation coefficients among the observed variables are shown in Table 2. All the correlations reported are statistically significant $(p<.01)$. Examination of the zero-order correlations indicates that the effects are relatively stable, as the 
Table 3. Test of stability effects and nested models

\begin{tabular}{|c|c|c|c|c|c|c|c|c|}
\hline & \multirow[b]{3}{*}{ d.f. } & \multirow[b]{3}{*}{$\Delta$ d.f. } & \multicolumn{6}{|c|}{ Job satisfaction } \\
\hline & & & \multicolumn{2}{|c|}{ Overall } & \multicolumn{2}{|c|}{ Intrinsic } & \multicolumn{2}{|c|}{ Extrinsic } \\
\hline & & & $\chi^{2}$ & $\Delta \chi^{2}$ & $\chi^{2}$ & $\Delta \chi^{2}$ & $\chi^{2}$ & $\Delta \chi^{2}$ \\
\hline Model A & 6 & & 139.02 & & 156.91 & & 50.25 & \\
\hline Model B & 10 & 4 & 139.42 & 0.40 & 158.74 & 1.83 & 55.88 & 5.63 \\
\hline Model C & 11 & 1 & 144.54 & 5.12 & 163.70 & 4.96 & 56.39 & $0.51 *$ \\
\hline Model D & 11 & 1 & 144.91 & 5.49 & 165.48 & 6.74 & 62.28 & 6.40 \\
\hline
\end{tabular}

$* p<.05$.

Note. $\Delta$ (delta) indicates changes. Model $\mathrm{A}=$ baseline model with no equality constraint imposed; Model $\mathrm{B}=$ baseline model with equality constraint imposed; Model $\mathrm{C}=$ model with the path from $\mathrm{JP} \rightarrow \mathrm{IS}$ eliminated from Model B; Model $\mathrm{D}=$ model with the path $\mathrm{JS} \rightarrow \mathrm{JP}$ eliminated from Model B. Model C and Model D are compared to Model B, respectively.

difference in correlations across time is small. For example, the correlation between JP1 and JP2 is .62, whereas that between JP2 and JP3 is .60; the correlation between JP1 and OJS2 is .46, whereas that between JP2 and OJS3 is .43. This pattern of correlations should illustrate stability instead of consistent shifts within the whole sample over time (Newton \& Kennan, 1991) because the means and standard deviations reported in Table 1 are similar over time for all the measures.

Next, we examined the statistical significance of the stability effects. We compared the model with no equality constraints imposed (Model $A$ ) to the one with equality constraints imposed, as described above. Specifically, an equality was imposed on four sets of parameters (job perception: $\gamma 11=\beta 31$; job satisfaction: $\gamma 22=\beta 42$; job perception to job satisfaction: $\gamma 21=\beta 41$; and job satisfaction to job perception: $\gamma 12=\beta 32$ ). The chi-square statistics and the model comparison results are reported in Table 3 . In this table, the constrained models (Model B) were compared to their respective baseline unconstrained models (Model A). As indicated in the table, none of the chi-square changes were statistically significant, even at the $p<.10$ level. This indicates that the effects investigated in this study were stable over time. Thus, subsequent analyses involved only models with equality constraints imposed on all relevant parameters.

\section{Preliminary examination of causal effects}

As indicated in Table 2, the correlations of the same measures across time for all the variables are reasonably high (from .49 to .62). The correlations between the three measures of job perception range from .49 to .62 , of overall job satisfaction from .53 to .60 , of intrinsic job satisfaction from .49 to .60 , and of extrinsic job satisfaction from .53 to .62. A preliminary examination of the zero-order correlation indicates that job perception and the three components of job satisfaction are correlated significantly across the three time periods. The significant 
cross-lag correlations indicate the possibility of reciprocal relationships betwcen job perception and the three components of job satisfaction. For example, the correlation between JP1 and OJS2 is .46 and that between JP2 and OJS3 is .43, whereas that between OJS1 and JP2 is .45 and that between OJS2 and JP3 is .42. A similar pattern of cross-lag correlations was observed between job perception and the other two components of job satisfaction. To examine the causal relationship between job perception and job satisfaction, we relied on the more rigorous model testing procedure stated above. The results of these tests are discussed in the next section.

\section{Causal direction}

Because cross-lagged correlations may not reflect the actual causal relationship between the constructs (Markus, 1979, pp. 48-49), the causal direction between job perception and job satisfaction was examined by the formal testing procedure of nested models. We performed all the nested model comparisons for the three baseline models (i.e. the three involving overall, intrinsic and extrinsic job satisfaction). To create the nested models, either the job perception to job satisfaction (Model $\mathrm{C}$ in Table 3) or the job satisfaction to job perception (Model $\mathrm{D}$ in Table 3) paths were set to equal zero. The nested models were then compared to their respective baseline model (Model $\mathrm{B}$ in Table 3). Chi-square values for each model and the chi-square changes are reported in Table 3. Results in Table 3 indicate that all the nested models (Model C and Model D) were significantly different from their respective baseline model (Model B), with one exception. When the paths from job pcrception to extrinsic job satisfaction were set to equal zero (Model C: extrinsic job satisfaction), the model was not significantly different from its bascline model (Model B: extrinsic job satisfaction). This indicates that job perception did not significantly predict extrinsic job satisfaction, even though extrinsic job satisfaction significantly predicted job perception. Overall and intrinsic job satisfaction, however, were significantly and reciprocally related to job perception. The path coefficients for the three final models are reported in Table 4.

As indicated in Table 4, all the path coefficients are significant except for the causal path from job perception to extrinsic job satisfaction. The results indicate that job perception and the various components of job satisfaction are reciprocally related except for extrinsic job satisfaction. Extrinsic job satisfaction has an effect on job perception, but not vice versa.

To examine whether the causal relationship is stronger in one dircction than in the reverse direction, we imposed the equality constraints on the causal paths between job satisfaction and job perception (i.e. $\gamma 21=\gamma 12=\beta 41=\beta 32$ ) for the two models with significant reciprocal causation. We then compared these models to the unconstrained models (i.e. Model B: overall job satisfaction and Model B: intrinsic job satisfaction in Table 3). The chi-square for the overall job satisfaction model with equality constraints imposed was $\chi^{2}(11)=139.42$; for the intrinsic job satisfaction model, $\chi^{2}(11)=158.84$. These chi-square values are not significantly different from their respective bascline models. Results of this analysis indicate that the two causal paths are not significantly different from each other regardless of 
Table 4. Estimated parameters for the three cross-lagged models involving different components of job satisfaction

\begin{tabular}{|c|c|c|c|}
\hline \multirow[b]{2}{*}{ Paths/Models } & \multicolumn{3}{|c|}{$\begin{array}{l}\text { Cross-lagged models: } \\
\text { Estimation of job satisfaction }\end{array}$} \\
\hline & Overall & Intrinsic & Extrinsic \\
\hline $\mathrm{JP} 1 \leftarrow \rightarrow \mathrm{JS} 1$ & $.68^{*}$ & $.75^{*}$ & $.45^{*}$ \\
\hline$J P 1 \rightarrow J P 2 \rightarrow J P 3$ & $.63^{*}$ & $.59 *$ & $.65^{*}$ \\
\hline $\mathrm{JS} 1 \rightarrow \mathrm{JS} 2 \rightarrow \mathrm{JS} 3$ & $.64 *$ & $.64^{*}$ & $.81 *$ \\
\hline $\mathrm{JP} \rightarrow \mathrm{JS}$ & $.14^{*}$ & $.16^{*}$ & .04 \\
\hline $\mathrm{JS} \rightarrow \mathrm{JP}$ & $.14^{*}$ & $.19^{*}$ & $.14^{*}$ \\
\hline CFI & .78 & .76 & .90 \\
\hline
\end{tabular}

whether we are dealing with intrinsic or overall job satisfaction. This suggests that it is just as likely for job perception to affect intrinsic or overall job satisfaction as vice versa.

\section{Discussion}

\section{Key findings}

The key findings of the present study are, first, that overall and intrinsic job satisfaction are reciprocally related to job perception, and this reciprocal causal relationship appears to be just as strong from one causal direction to the other. Second, job perception did not have causal effects on extrinsic job satisfaction, but the latter had causal effects on the former. Since overall job satisfaction is a composite measure of intrinsic and extrinsic job satisfaction, we can deduce that job perception mainly has effects on the intrinsic component of overall job satisfaction. Nevertheless, the reciprocal relationship found between job perception and intrinsic job satisfaction provides clear support for CSL theory.

The JCM and SIP theory do not receive as clear support as CSL theory because one can deduce neither the effect of intrinsic job satisfaction on job perception from the JCM, nor the effect of job perception on overall job satisfaction from SIP theory.

\section{Implications for the three theories}

The findings of this study may have important implications for the three theories. The JCM focuses primarily on the effects of objective job content on outcome variables such as job satisfaction. Even though the relationship between objective job content and subjective job perception is not directly considered in the model, it is often implied that the objective job content determines subjective job 
perception, which in turn determines job satisfaction (Spector, 1992). The results of this study indicate that to further develop the JCM, researchers have to state explicitly the relationship between objective job characteristics and job perception. They have to acknowledge the possibility that job perception could be influenced by factors other than the objective job content as the CSI theory does. With this amendment, JCM researchers could still concentrate their efforts in describing the causal effect of objective job characteristics on job perception but be able to accommodate the possible effect of job satisfaction on job perception.

Job perception is defined in SIP theory through social constructs. SIP theory researchers argue that job characteristics are socially constructed (Salancik \& Pfeffer, 1978, p. 227) and social information, not objective job content, has a predominant effect on job perception. Objective job content in SIP theory plays a very minor or even no role in the job perception-job satisfaction relationship. The results of past job design studies may have already provided evidence to reject this position. Although some studies have demonstrated that social cues and individual factors (e.g. age and sex) have an effect on perceived job characteristics (e.g. Ferris, 1983; Ferris, Fedor, Rowland \& Porac, 1985; O'Connor \& Barrett, 1980; O'Reilly \& Caldwell, 1979; O’Reilly, Parlette \& Bloom, 1980; Weiss \& Shaw, 1979; White \& Mitchell, 1979), many other studies have indicated that manipulation of the objective job contents produced changes in the perception of job characteristics (e.g. Farh \& Scott, 1983; Farr, 1976; Griffin, 1983; Kim, 1980; Iawler et al., 1973; O'Connor $t$ al., 1981; Terborg \& Davis, 1982; Wall \& Clegg, 1981). The results of these studies suggest that job perception is a function of both the objective job characteristics and the relevant social information. Thus, the assumption of SIP theory that job perception is merely constructed from social information may be too extreme. To overcome this difficulty, researchers of SIP theory would have to accommodate the role of objective job characteristics. Conceptually, objective job characteristics themselves may become a source of social cues and information. For example, having greater responsibilities than one's subordinates and producing identifiable outcomes that have an impact on other employees may become relevant pieces of social information for one to perceive one's own job. Thus, the employee's job perception may reflect partly objective job characteristics. This argument is consistent with SIP theory, which emphasizes the importance of social information.

It must be stressed here, as some reviewers have done (e.g. Zalesny \& Ford, 1990), that Salancik \& Pfeffer (1978) did not intend to present a fully developed theory. Their intention was to provide an alternative to the need-based models of motivation. Modifying the original assumption of SIP theory about the correspondence between objective and perceived job characteristics helps resolve its contradiction with the other two theories.

CSL theory does not account for the causal effects of extrinsic job satisfaction on job perception. Nonetheless, it is possible to incorporate extrinsic job aspects into the conceptualization of social information in CSI theory. As stated above, CSL theory suggests that employees form their job perceptions by assigning unique meanings to their work situations based on their jobs and other relevant social information. It may well be that relevant social information includes information 
about extrinsic aspects of the job. I'hus, CSL theory might regard extrinsic job satisfaction as an important source of social information that employees rely on to form their job perceptions. With this recognition of the importance of both intrinsic and extrinsic job satisfaction, the present findings are totally consistent with an interaction framework for the relationship between job perception and job satisfaction. Another possible amendment of CSI theory would be to adopt the JCM's position that argues that extrinsic job satisfaction may affect job incumbents' 'willingness or ability to take advantage of the opportunities for personal accomplishment provided by enriched work' (Hackman \& Oldham, 1980, p. 86). Thus, incumbents with higher levels of extrinsic job satisfaction will have a greater chance to realize and perceive their jobs as more motivating and challenging.

\section{Practical implications}

The result of this study indicate that the major recommendations of the three theories (i.e. enhancing the objective job characteristics from JCM, and cultivating social information from SIP theory and CSL theory) may all be valid. For example, job design or other intervention programmes can increase intrinsic job satisfaction so far as the incumbents can perceive their jobs to have become more motivating. Increases in intrinsic job satisfaction could further induce incumbents' favourable perception of the jobs. This interactive process suggests that the best results of job design may come from the combination of the sound manipulations of job characteristics and the cultivation of a job environment full of positive social information.

\section{limitations}

There are four limitations to the present study. The first one is the lack of objective job characteristic measurements, because the JCM suggests that it is objective job characteristics that form the basis for job perception. Instead, we merely assumed a correspondence between objective job characteristics and subjective job perception. Without indices of objective job content, one may still argue that the job perception we measured was contaminated by social information. It should be noted, however, that in a static sense there can be no debate over the possible causal direction between objective job characteristics and job satisfaction, as attitudes and perception cannot change objective job characteristics. If objective job characteristics, job perception and job satisfaction are causally related, objective job characteristics must be the cause and not the effect. Thus, the focal issue is always the causal relationship between job perception and job satisfaction.

It is possible that objective job characteristics may be changed over time due to job perception. For example, one may use different job methods by developing new work-aids over time in order to get the same job results if one perceives the old methods as boring or inappropriate. It is also possible that changes in objective job conditions do not necessarily impact job perception if the changes are being interpreted differently in the particular social context or simply being considered as 
trivial. However, the effects of these phenomena should be very limited, especially when the observations are made over a long period of time. Also, the effects, if they really exist, will be non-systematic in our sample because research participants work for different organizations. Furthermore, in both research and the workplace, the distinction between objective job characteristics and subjective job perception is blurred. In terms of research, measuring objective job content almost implies measuring people's perception of job content (i.e. job perception), unless one can manipulate the job content to be studied. Also, both conceptually and practically, it is not always what is actually in the workplace, but what is perceived to be in the workplace, that affects work outcomes. In short, we believe that the study of the causal relationship between job perception and job satisfaction is still important and our longitudinal design with a relatively long observation period should be able to examine this relationship.

Second, we have operationalized job perception by the theory-based MPS. This multiplicative formulation of MPS has been criticized by some reviewers and they suggest a simple average as an alternative measure (e.g. Roberts \& Glick, 1981). Past studies using the structural equation modelling method have used the individual job characteristics as indicators of job perception. Therefore, we conducted the same LISREI, analysis using the simple average of all items rather than the MPS as the single indicator of job perception, and the five job characteristics as individual indicators. Results using the simple average operationalization of job perception are similar to the multiplicative formulation. Results are also similar in the five indicator analysis except for the effect of extrinsic job satisfaction on job perception, which fails to reach the level of statistical significance $(t$ value $=1.51$ ). It is unclear whether this is the result of specifying the five job characteristics wrongly as 'effect' rather than 'cause' indicators (Bollen \& Lennox, 1991; Law \& Wong, 1996; Law, Wong \& Mobley, 1996; MacCallum \& Browne, 1993), or simply the result of reducing statistical power as more parameters have to be estimated in the LISREL analyses. Results of these two additional analyses indicate that the operationalization of job perception used in this study do not appear to invalidate the final conclusion.

Third, measures of this study are self-reported and so the effect of common method variances (Spector, 1992, 1994) may have affected the results. To deal with this potential threat, we have utilized the longitudinal design to examine the one-year, cross-lagged effects between job perception and job satisfaction. This design could help reduce the common method variances among the measures (Spector, 1992, 1994). Furthermore, 'existing data fail to support the notion that common method variance is an important cause of observed relations among self-report scales in the job conditions domain' (Spector, 1992, p. 143). Nevertheless, we conducted the same LISRLL, analyses after partialling out some irrelevant variables, which should not have a direct relationship with both job perception and job satisfaction. In designing the study, we have included two irrelevant measures. The first one is a five-item measure (average coefficient alpha for the three surveys $=.76$ ) of need for achievement (Steers \& Braunstein, 1976). The second one is a single item that requires the research participants to respond on a five-point Likert-type scale (ranging from 'strongly agree' to 'strongly disagree') to 
the statement: 'I am an average worker'. After partialling out each of these irrelevant measures, the LISREL results are similar except that the path coefficients became smaller. Thus, common method variances did not appear to invalidate the results of this study.

Finally, the correlations among the measures may have been inflated by dispositional variables such as negative affectivity (Burke, Brief \& George, 1993; Newton \& Keenan, 1991). Unfortunately, it is beyond the scope of this study to come up with an exhaustive list of all possible dispositional variables and control all of them. Thus, although all the correlations will be inflated by dispositional variables, it is possible that the stability of job perception and job satisfaction over time may be affected to a greater extent. Future research may concentrate on the effects of dispositional variables in order to cross-validate the findings in this study.

In conclusion, noting the lack of adequate comparative studies on the three alternative specifications of the causal direction between job perception and job satisfaction, we designed a longitudinal study to examine this causal relationship. We found evidence for a reciprocal relationship between job perception and job satisfaction. The findings pointed to suggestions for further development of the three underlying theories and the importance of considering the interactive process between job perception and job attitudes.

\section{References}

Anderson, J. C. \& Gerbing, D. W. (1988). Structural equation modeling in practice: A review and recommended two-step approach. Psychologial Bulletin, 103, 411-423.

Anderson, S. E. \& Williams, I. J. (1992). Assumptions about unmeasured variables with studies of reciprocal relationships: The case of employee attitudes. Journal of Applied Psychology, 77, 638-650.

Bollen, K. A. (1989). Structural Equations with Latent Variables. New York: Wiley.

Bollen, K. A. \& Lennox, R. (1991). Conventional wisdom on measurement: A structural equation perspective. Psychological Bulletin, 110, 305-314.

Brislin, R. W. (1970). Back-translation for cross-cultural research. Journal of Cross-Cultural Psychology, 1 , $185-216$

Burke, M. J., Brief, A. P. \& George, J. M. (1993). The role of negative affectivity in understanding relations between self-reports of stressors and strains: $A$ comment on the applied psychology literature. Joumal of Applied Psychology, 78, 402-412.

Caldwell, D. F. \& O'Reilly, C. A. III (1982). Task perceptions and job satisfaction: A question of causality. Joumal of Applied Psychology, 67, 361-369.

Campion, M. A. \& McClelland (1993). Follow-up and extension of the interdisciplinary costs and benefits of cnlarged jobs. Journal of Applied Psychology, 87, 339-351.

Chun, K. T., Campbell, J. B. \& Yoo, J. H. (1974). Extreme response style in cross-cultural research. Journal of Cross-Cultural Psycbology, 5, 465-480.

Cohen, J. \& Cohen, P. (1975). Applied Multipla Regression/Correlation Analysis for the Bebanioral Sitences. New York: Wiley.

Cook, J. D., Hepworth, S. J., Wall, T. D. \& Warr, P. B. (1981). The Experience of Work: A Compendium and Review of 249 Measures and Their Use. London: Academic Press.

Cordery, J. L., Mueller, W. S. \& Smith, I. M. (1991). Attitudinal and bchavioral effects of autonomous group working: A longitudinal field study. Academy of Management Journal, 34, 464-476.

Farh, J. L. \& Scott, W. E. (1983). The experimental effects of 'autonomy' on performance and self-reports of satisfaction. Organizational Behavior and Human Performance, 31, 203-222.

Farr, J. L. (1976). Task characteristics, reward contingency, and intrinsic motivation. Organizational Behawior and Human Performance, 16, 294-307. 
Ferris, G. R. (1983). The influence of leadership on perceptions of job autonomy. Journat of Psychologs, 114, 253-258.

Ferris, G. R., Fedor, D. B., Rowland, K. M. \& Porac, J. F. (1985). Social influence and sex effects on task performance and task perceptions. Journal of Tocational Betzavior, 26, 66-78.

Firied, Y. (1991). Meta-analytic comparison of the job diagnostic survey and job characteristics inventory as correlates of work satisfaction and performance. Joumal of Applied Psyology', 76, $690-697$.

Fried, Y. \& Ferris, G. R. (1987). The validity of the job characteristics model: A review and meta-analysis. Personnel Psychology, 40, 287-322.

Gerbing, D. W. \& Anderson, J. C. (1993). Monte Carlo evaluations of goodness-of-fit indices for structural equation models. In K. A. Bollen \& J. S. Long (Lds), Tisting Strutural Eiquation Hodels, pp. 40-65. Newbury Park, CA: Sage.

Griffin, R. W. (1983). Objective and social sources of information in task redesign: A field experiment. Administrative Science Quarterly, 28, 184-200.

Griffin, R. W. (1991). Feffects of work redesign on employee perceptions, attitudes, and behariors: $A$ long-term investigation. Academy of Munagement Joumal, 34, 425-435.

Hackman, J. R. \& Oldham, G. R. (1975). Development of the job diagnostic survey. Joumat of -1pphed Psychology, 60, 159-170.

Hackman, J. R. \& Oldham, G. R. (1976). Motivation through the design of work: Test of a theory. Organizationat Behanior and Human Performance, 16, 250-279.

Hackman, J. R. \& Oldham, G. R. (1980). Work Redesign. Reading, MA: Addison-Wesley.

Hoadley, J. S. (1970). 'Hong Kong is the lifeboat': Notes on political culture and socialization. Journal of Oriental Studies, 8, 206-218.

Hulin, C. L. \& Blood, M. R. (1968). Job enlargement, individual differences, and worker responses. Pychological Bulletin, 69, 41-55.

Hunter, J. E. \& Gerbing, D. W. (1982). Unidimensional measurement, second order factor analysis, and causal models. Researb in Organizitional Behavior, 4, 267-320.

James, L. R., Hater, J. J., Gent, M. J. \& Bruni, J. R. (1978). Psychological climate: Implication from social learning theory and interactional psychology. Personnel Psyology, 31, 781-813.

James, L. R. \& Jones, A. P. (1980). Perceived job characteristics and job satisfaction: An examination of reciprocal causation. Personnel Psychology, 33, 97-135.

James, L. R., Mulaik, S. S. \& Brett, J. M. (1982). Catsal Anatysis, Asmmptions, Models, and Data. Beverly Hills, CA: Sage.

James, L. R. \& Tetrick, I. E. (1986). Confirmatory analytic tests of three causal models relating job perceptions to job satisfaction. Joumal of Applied Psychology, 71, 77-82.

Jöreskog, K. G. \& Sörbom, D. (1989). I.ISRI:L VII User's Reference Guide. Mooresville, IN: Scientific Software.

Jöreskog, K. G. \& Sörbom, D. (1993). LISRLL 8 User's Reference Guide. Mooresville, IN: Scientific Software.

Kenny, D. A. (1979). Correlation and Causality. New York: Wiley.

Kim, J. S. (1980). Relationships of personality to perceptual and behavioral responses in stimulating and nonstimulating tasks. Academy of Management journal, 23, 307-319.

Iaw, K. S. \& Wong, C. S. (1996). The implications for multidimensional constructs in covariance structure. Annual Conference of the Society for Industrial \& Organizational Psychology, San Diego, April.

Law, K. S., Wong, C. S. \& Moblcy, W. H. (1996). Towards a taxonomy of multidimensional constructs. Paper presented at the Academy of Management Annual Meeting, Cincinnati, OH, August.

Lawler, E. E., Hackman, J. R. \& Kaufman, S. (1973). Effects of job redesign: A field experiment. Joumal of Applied Social Psychology, 3, 49-62.

Levacic, R. (1976). Macroconomics: The Static and Dynamic 1nalysis of a Montan Fonomy. Iondon: Macmillan.

Loher, B. T., Noe, R. A., Moellet, N. L. \& Fitzgerald, M. P. (1985). A meta-analysis of the relation of job characteristics to job satisfaction. Journal of 1pplied Piscbology, 70, 28(1)-289. 
MacCallum, R. C. \& Browne, M. W. (1993). The use of causal indicators in covariance srructure models: Some practical issues. Pisdoloyical Bulletin, 114, 533-541.

Markus, G. B. (1979). Analyzing Panel Data. Beverly Hills, CA: Sage.

Mathieu, J. F. (1991). A cross-level nonrecursive model of the antecedents of organizational commitment and satisfaction. Joumal of Applied Psycbology, 67, 53-50.

Mathieu, J. E., Hofmann, D. A. \& Farr, J. I. (1993). Job perception-job satisfaction relations: An empirical compatison of three competing theorics. Organizationat Behatior and Human Deation Processes, 56, 370-387.

Mayo, F. (1933). The Luman Problens of an Industrial Cinilization. New York: Macmillan.

Mever, J. P., Allen, N. J. \& Gellatly, I. R. (1990). Affective and continuance commitment to the organization: Fvaluation of measures and analysis of concurrent and time-lagged relations. Joumat of -1pplied Psychology, 75, 710-720.

Newton, T. \& Keenan, A. (1991). Further analysis of the dispositional argument in organizational behavior. Joumal of Applied Psychology, 76, 781-787.

O'Connor, F. J., Arnold, G. C. \& Bhagat, R. S. (1981), Job design task attributes: An cvaluation of prior manipulations based on a retranslation technique. Joumal of Management, 7, 9-16.

O'Connor, E. J. \& Barrett, G. V. (1980). Informational cues and individual differences as determinants of subjective perceptions of task enrichment. Aademy of Management Joumal, 23, 697-716.

O'Reilly, C. A. \& Caldwell, D. F. (1979). Information intluence as a determinant of perceived task characteristics and job sarisfaction. Joumd of Applied Psychology, 64, 157-165.

O'Reilly, C. A., Parlette, G. N. \& Bloom, J. R. (1980). Perceptual measures of task characteristics: The biasing in personality, position in the organization, and job satisfaction. Organizational Bebarior and Human Performane, 14, 144-150.

Orpen, C. (1979). The effects of job enrichment on employee satisfaction, motivation, involvement, and performance: $A$ field experiment. Husmom Relations, 32, 189-217.

Persson, T. \& Tabellini, G. (1990). Macroconomic Poliog, Credibitity and Politics. Vew York: Harwood.

Podmore, D., Chaney, D. \& Golder, P. (1975). 'Don't know' responses among young adults in Hong Kong. Joumat of Sicial Psycholog;, 96, 307-308.

Roberts, K. H. \& Glick, W. (1981). The job characteristics approach to task design: A critical review. Joumal of Applied Psychology, 66, 193-217.

Salancik, G. R. \& Pfeffer, J. (1978). A social infurmation processing approach to job attitudes and task design. Administrative Siche Quarterly, 23, 224-253.

Schaubroeck, J., Ganster, D. C., Sime, W. E. \& Ditman, D. (1993). A field experiment testing supervisory role clarification. Personnel Psychology, 46, 1-25.

Spector, P. F. (1992). A consideration of the validity and meaning self-rcport measures of job conditions. Intemational Reviem of Industrial and Organizational Psychologi, 7, 123-151.

Spector, P. F. (1994). Using self-report questionnaires in ()B rescarch: A comment on the use of a controversial method. Joumal of Organizational Betawivi, 15, 385-392.

Steers, R. M. \& Braunstein, D. N. (1976). A behaviorally-based measure of manifest needs in work settings. Joumat of locational Behavior, 9, 251-266.

Stone, E. F. (1976). The moderating effect of work-related values on the job scope-job satisfaction relationship. Organizational Bebalior and Human Performance, 15, 147-167.

Stonc, E. F. (1986). Job scope-job satisfaction and job scope-job performance relationships. In F.. A. Locke (Eds), Generalizing from Laboratory to Fild Settings, Lexington, MA: Lexington Books.

Stone, E. F. (1992). A critical analysis of social information processing models of job perceptions and job attitudes. In C. J. Cranny, P. C. Smith \& E. F. Stone (Eds), Job Satisfation, pp. 21-44. New York: Lexington Books.

Terborg, J. R. \& Davis, G. A. (1982). Evaluation of a new method for assessing change in planned job redesign as applied to Hackman and Oldham's job characteristics model. Organizational Bebatior and Human Performance, 29, 112-128.

Thomas, J. \& Grifin, R. (1983). The social information processing model of task design: A roview of the literature. Academy of Management Retiem, 8, 672-682.

Wall, T. D. \& Clegg, C. W. (1981). A longitudinal field study of group work rodesign. Joumat of Occupational Bebavior, 2, 31-49. 
Wall, T. D., Kcmp, N. J., Jackson, P. R. \& Clegg, C. W. (1986). Outcomes of autonomous workgroups: A long-term field experiment. Aadeny of Management Journal, 29, $280-304$.

Weiss, D. J., Dawis, R. V., England, (B. W. \& Lofquist, I. H. (1967), Mannal for the Minnesota Satigfaction Questionnaire: Minnesota Studies in Vocational Rebabilitation. Minncapolis: Industrial Relations Conter, University of Minnesota.

Weiss, H. M. \& Shaw, J. B. (1979). Social influences on judgments about tasks. Organizational Bebutor and Fuman Performance, 24, 126-140.

White, S. E. \& Mitchell, T. R. (1979). Job enrichment versus social cues: A comparison and competitive test. Journal of Applied Psychology, 64, 1-9.

Williams, I. J. \& Hazer, J. T. (1986). Antecedents and consequences of satisfaction and commitment in turnover models: A reanalysis using latent variable structural equation models. Jouthat of lpp/ied Psychology, 71, 219-231.

Williams, L. J. \& Podsakoff, P. N. (1989). Longitudinal field methods for studying reciprocal relationships in organizational behavior research: Toward improved causal analysis. Research in Organizational Behavior, 11, 247-292.

Wong, C. S. \& Law, K. S. (1996). Testing teciprocal causation by nonrecursive structural equation models using cross-sectional data. Paper presented at the Academy of Management Annual Meeting, Cincinnati, $\mathrm{OH}$, August.

Yang, K. S. (1982). Institute of Ethnology, Acadenic Sinica, Monograpt Seriss B, No. 10, pp. 153-188. Nankang, Taipei, Republic of China: Institute of Ethnology (In Chinese).

Zalesny, M. D. \& Ford, J. K. (1990). Fxtending the social information processing perspective: New links to attitudes, behaviors, and perceptions. Organizational Behatior and Hhman Decision Protests, 47, 205-246. 